\title{
Anterior Bridging Bronchus
}

\author{
Thomas J. Rishavy, MD, Michael J. Goretsky, MD, Scott E. Langenburg, MD, \\ and Michael D. Klein, MD*
}

\begin{abstract}
Summary. Previously reported patients with a bridging bronchus (BB) presented with respiratory distress. In addition, each patient had one or more associated anomalies. All but two patients progressed to cardiopulmonary failure and death. We describe a case of an anterior BB without associated anomalies, who did well without operative intervention. This patient presented with a cough at 6 months of age. Chest X-ray was normal, but due to suspicion of foreign body aspiration, bronchoscopy was performed, which revealed a third bronchus at the carina. Bronchography demonstrated the anatomy of the BB. The patient has continued to do well without further intervention. Pediatr Pulmonol. 2003; 35:70-72. ๑ 2003 Wiley-Liss, Inc.
\end{abstract}

Key words: airway anomalies; bridging bronchus; cough.

\section{INTRODUCTION}

The anomaly of a bridging bronchus (BB) is extremely rare. Since the original report by Gonzalez-Crussi et al. in $1976,{ }^{1}$ only 8 other cases of this anatomic variation have been reported. ${ }^{2-9}$ In this anomaly (Fig. 1C), the right lower (and often middle) lobe is supplied by a bronchus which originates from the left main bronchus and crosses (bridges) the mediastinum. A sling left pulmonary artery (SLPA) is often associated with a BB. In SLPA (Fig. 1B), the left pulmonary artery originates from the right pulmonary artery and reaches the left lung by passing behind the trachea and in front of the esophagus. This sling is usually associated with an intrinsic stenosis of the trachea. Our patient was found to have an accessory bronchus emanating from the distal anterior aspect of her carina with no SLPA. This third bronchus bridged over the mediastinum to the right lower lobe of the lung. To our knowledge, this is the first description of an anterior BB. In addition, this is the first report of a BB in an asymptomatic patient.

\section{CASE REPORT}

Our patient was born at term by spontaneous vaginal delivery without complications. At 5 months of age, she presented with coughing and wheezing. She was diagnosed with bronchiolitis, treated, and sent home. One month later, she was admitted because her condition had not improved. We were asked to see the patient because of suspected foreign body aspiration. We performed rigid bronchoscopy. This revealed a normal trachea and bronchi, except for a small opening in the anterior aspect of her carina. A repeat bronchoscopy (Fig. 2) and follow-up bronchogram (Fig. 3) (performed 2 weeks later) revealed a third bronchus coming from the (c) 2003 Wiley-Liss, Inc. carina on the right side. The BB crossed the mediastinum to the right lower lobe. The tracheal bifurcation was noted to be in a normal anatomic position at the level of T5. She was asymptomatic following the first bronchoscopy, and continues to be so 1 year later.

\section{DISCUSSION}

Bridging bronchus is often associated with an SLPA. SLPAs have been subdivided into four types. ${ }^{8}$ It is type II that is associated with a BB. This type has a normal right bronchus supplying the right upper lobe and a BB from the left supplying the right middle and lower lobes. Type IIB has only the $\mathrm{BB}$ (no right main bronchus) supplying a (usually) hypoplastic right lung.

In addition, variations of BB have been reported. ${ }^{5-8}$ In 1981, Starshak et al. ${ }^{7}$ reported an infant whose right lower lobe bronchus arose from the left main bronchus and bridged the lower mediastinum. This child had an imperforate anus and died within 3 weeks of birth. A similar child was presented by Bertucci et al. ${ }^{4}$ in 1987; however, this patient had the left main pulmonary artery positioned posterior to the left main-stem bronchus. Most of the early reports found the BB at autopsy. There is one

Department of Surgery, Wayne State University School of Medicine, and Department of Surgery, Children's Hospital of Michigan, Detroit, Michigan.

*Correspondence to: Michael D. Klein, M.D., Department of Pediatric Surgery, Children's Hospital of Michigan, 3901 Beaubien Blvd., Detroit, MI 48201. E-mail: mklein@dmc.org

Received 19 February 2001; Accepted 21 August 2002.

DOI 10.1002/ppul.10205

Published online in Wiley InterScience (www.interscience.wiley.com). 

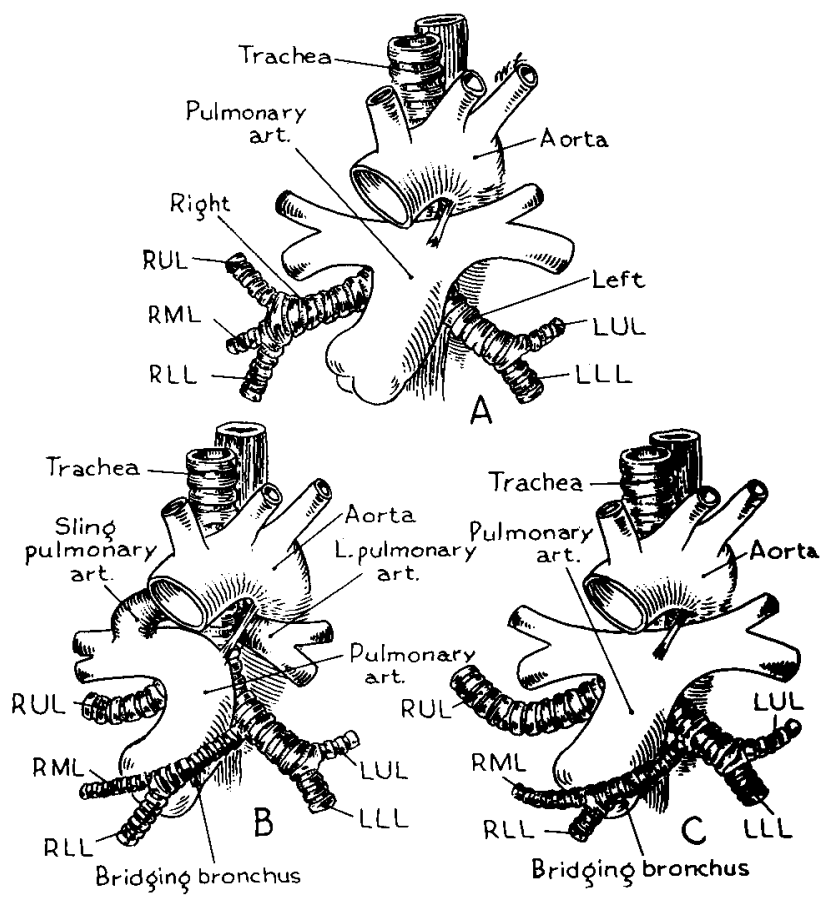

Fig. 1. A: Diagram of normal relationships of tracheobronchial tree and pulmonary artery. B: Bridging bronchus with sling left pulmonary artery (SLPA). C: Bridging bronchus without SLPA. case of successful repair of a BB. After dividing and reanastomosing the SLPA, the surgeons reconstructed the long thin segment of the airway from the carina to the pseudocarina, using auricular cartilage from the patient's right ear.

It could be argued that the bronchogram in Figure 3 represents a low carina with the right upper lobe bronchus coming directly off the trachea. ${ }^{10}$ This has been called an eparterial bronchus, pig bronchus, or bronchus suis. ${ }^{11,12}$ The bronchus suis is described as coming off the trachea, directed laterally at a right angle, while in our case the takeoff was distinctly inferior and oblique. We also feel that the large size of the orifice noted on bronchoscopy of what we choose to call the right main-stem bronchus makes it more likely to be this. In addition, this more cephalad bronchus on the bronchogram appears to supply both the upper and middle lobes, while the BB supplies the lower lobe, as described in the original case report by Gonzalez-Crussi et al. ${ }^{1}$

Using multiple imaging and endoscopic techniques, a BB can be detected early. In addition to chest radiography and bronchoscopy, computed tomography, angiography, and bronchography have been used to evaluate this anatomic anomaly. With these techniques, variations

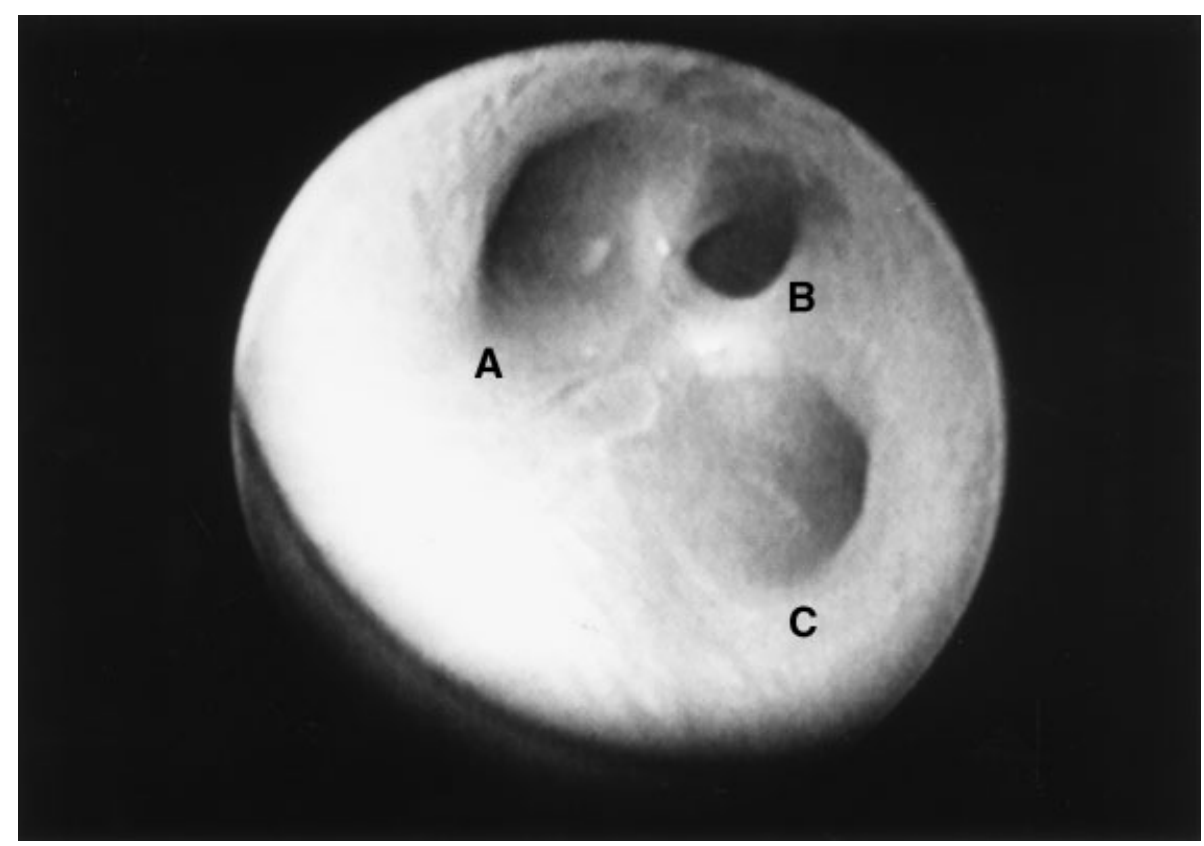

Fig. 2. Bronchoscopy, showing take-off of bridging bronchus (B) from left main-stem bronchus (A). C: Right main-stem bronchus.

\section{ABBREVIATIONS}

BB Bridging bronchus

SLPA Sling left pulmonary artery of BB have been described. Wheeler et al. ${ }^{5}$ reported on a reversed $\mathrm{BB}$ in which the right main-stem bronchus crossed the midline to supply the left lower lobe. These authors are strong proponents of bronchography because 


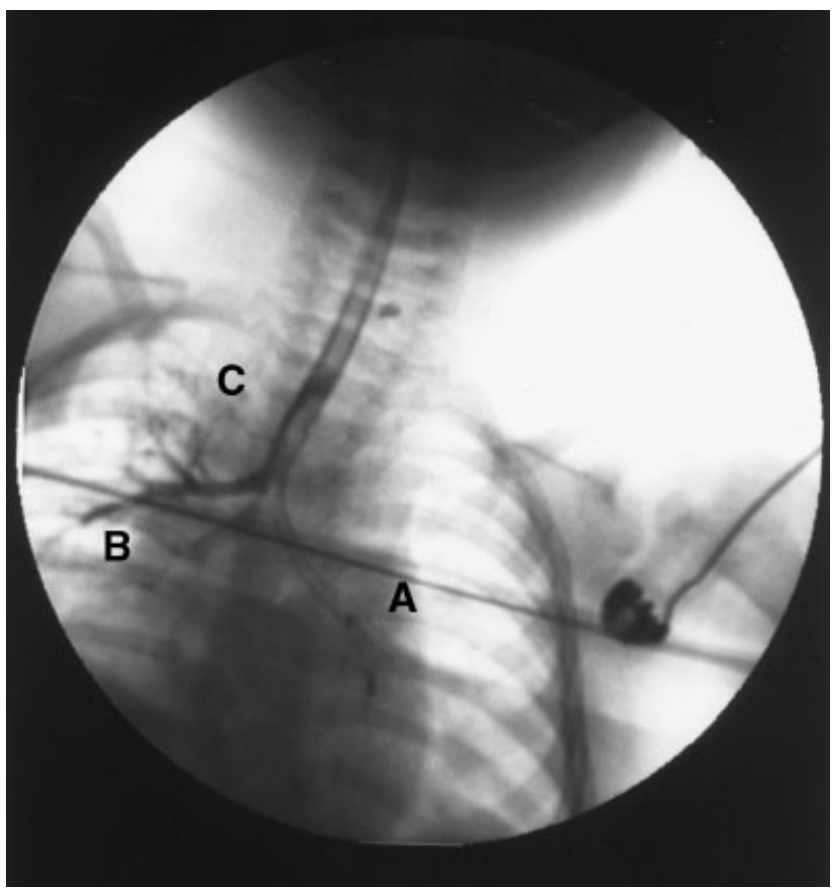

Fig. 3. Bronchogram showing bridging bronchus (B) taking off from left main-stem bronchus (A) and crossing the mediastinum to supply the right lung. C: Right main-stem bronchus.

of its utility in their case. In our case, the unusual findings at bronchoscopy led to bronchography, which was necessary to completely delineate the anatomy.

We feel that our case is unique for two reasons. First, our patient's BB emanated from the anterior position of the carina, unlike previously described origins. In addition, our patient was asymptomatic upon presentation, and has continued to do well without further intervention.

\section{REFERENCES}

1. Gonzalez-Crussi F, Padilla L-M, Miller JK, Grosfeld JL. Bridging bronchus: a previously undescribed airway anomaly. Am J Dis Child 1976;130:1015-1018.

2. Medina-Escobedo G, Lopez-Corella E. Sling left pulmonary artery, bridging bronchus, and associated anomalies. Am J Med Genet 1992;44:303-306.

3. Stokes JR, Sorkness RL, Kaplan MR, Castleman WL, Tomai MA, Miller RL, Lemanske RF Jr. The bridging bronchus-successful diagnosis and repair. Arch Otolaryngol Head Neck Surg 1997; 123:1344-1347.

4. Bertucci GM, Dickman PS, Lachman RS, Andrews J, Paulsen P. Bridging bronchus and posterior left pulmonary artery: a unique association. Pediatr Pathol 1987;7:637-643.

5. Wheeler DS, Poss WB, Cocalis M, Krumwiede G, Gaston B. Braided bronchus: a previously undescribed airway anomaly. Pediatr Pulmonol 1998;25:348-351.

6. Hawass ND, Badawi M, al-Muzrakchi A, al-Sammarai A, Jawad A, Abdullah M, Bahakim H. Horseshoe lung: differential diagnosis. Pediatr Radiol 1990;20:580-584.

7. Starshak RJ, Sty JR, Woods G, Kreitzer FV. Bridging bronchus: a rare airway anomaly. Radiology 1981;140:95-96.

8. Wells TR, Gwinn JL, Landing BH, Stanley P. Reconsideration of the anatomy of sling left pulmonary artery: the association of one form with bridging bronchus and imperforate anus: anatomic and diagnostic aspects. J Pediatr Surg 1988;10:892-898.

9. Wells TR, Stanley P, Padua EM, Landing BH, Warburton D. Serial section-reconstruction of anomalous tracheobronchial branching patterns from CT scan images: bridging bronchus associated with sling left pulmonary artery. Pediatr Radiol 1990; 20:444-446.

10. Skandalakis JE, Gray SW, Symbas PN. Trachea and lungs. In: Skandalakis JE, Gray SW, editors. Embryology for surgeons, 2nd ed. Embryology for surgeons, 2nd ed. Baltimore: Williams \& Wilkins; 1994. p 433.

11. Boyden EA. The distribution of bronchi in gross anomalies of the right upper lobe, particularly lobes subdivided by the azygous vein and those containing pre-eparterial bronchi. Radiology 1952;58:797-807.

12. Gikonyo BM, Jue KL, Edwards JE. Pulmonary vascular sling: report of seven cases and review of the literature. Pediatr Cardiol 1989;10:81-89. 